\title{
CENSO ESCOLAR E SISTEC: AS MAIS IMPORTANTES BASES DE COLETA DE DADOS PARA EPT
}

http://dx.doi.org/10.5902/2318133834593

\author{
Franciele de Lima Machado
}

\begin{abstract}
Resumo
O censo escolar e o Sistec destacam-se como ferramentas pelas quais busca-se oferecer suporte ao planejamento, execução e controle de ações voltadas à educação profissional e tecnológica. $A$ identificação de dificuldades com esses sistemas, frente a sua relevância para a gestão pública, justifica a necessidade de estudá-los. Este trabalho foi realizado mediante entrevistas semiestruturadas com professores de estabelecimentos das redes privada e pública do município de Santa Maria/RS. Procurou-se compreender estes sistemas, identificando suas principais dificuldades, sob a ótica de seus usuários. Constatou-se que os sistemas não funcionam como o planejado, e possuem uma série de problemas em seus mecanismos de treinamento, coleta, armazenamento, fiscalização e análise de dados.

Palavras-chave: EPT; censo escolar; Sistec.
\end{abstract}

\section{SCHOLAR CENSUS AND SISTEC: THE MOST IMPORTANT EPT DATA COLLECTION BASIS}

\begin{abstract}
The scholar census and Sistec are highlighted tools that offer support when planning, implementing and controlling the actions aimed at professional and technological education. This study is justified by the need of system difficulties identification, taking into account its value to public management. This study was conducted by taking semi-structured interviews with professors from public and private establishments from Santa Maria/RS. The study aimed to understand both systems while identifying its difficulties from the final user perspective. It was found that the systems does not work as planned and present a range of issues on its training, collecting, storing, inspecting and data analyzing tools.

Key words: EPT, scholar census, Sistec
\end{abstract}

${ }^{1}$ Colégio Técnico Industrial de Santa Maria, Brasil. E-mail: fran Im20@hotmail.com. 


\section{Introdução}

esde a regulamentação da educação profissional e tecnológica no Brasil, a partir da Lei de Diretrizes e Bases da Educação Nacional de 1996, e do decreto n. 5.154, de 2004, esse segmento educacional cresceu significativamente e, nos últimos anos, ganhou muita visibilidade em virtude do grande montante de investimentos federais e pela criação e melhorias de políticas públicas e programas que aumentaram o número de vagas e de instituições de ensino técnico no país (Brasil, 2016).

Segundo o governo federal, até o ano de 2023, os jovens do país na faixa etária dos quinze aos vinte e nove anos são e serão a maior força de trabalho da história, totalizando cerca de 50 milhões de pessoas, representando $26 \%$ da população brasileira. A grandiosidade desses números demonstra a importância de políticas públicas direcionadas à qualificação do ensino profissional no Brasil. Para que seja possível a avaliação, formulação e execução de ações e políticas públicas, o governo necessita de instrumentos que gerem indicadores que traduzam a realidade educacional brasileira. Para tanto, os dados devem ser estruturados, sistematizados, e, sobretudo, confiáveis, permitindo assim, que os indicadores sejam precisos e apresentem um panorama realista sobre o segmento em questão. No caso da EPT, as principais ferramentas utilizadas para essa finalidade são o Censo Escolar e o Sistema Nacional de Informações para Educação Profissional e Tecnológica - Sistec.

Em função disso realizou-se uma pesquisa exploratória, de natureza qualitativa, com vistas a produzir conhecimento em torno de vivências, interesses e necessidades, apoiado na realização de entrevistas semiestruturadas, com seis questões norteadoras, realizadas com usuários do Censo Escolar e Sistec. A amostra dos sujeitos entrevistados foi extraída da cidade de Santa Maria, no Estado do Rio Grande do Sul, e coletou informações com nove usuários dos sistemas: quatro da rede privada, três da rede federal, um da rede estadual e um da rede municipal. $O$ intuito principal das entrevistas foi contatar pessoas que trabalham diretamente com Censo Escolar e Sistec, nos módulos ligados aos "alunos e turmas/ciclos", percebendo suas impressões, dificuldades, forma de abastecimento, conhecimento sobre o trabalho desenvolvido e sobre os sistemas utilizados e sua importância, além de verificar suas condições gerais de trabalho. As análises e resultados sustentaram-se em levantamentos bibliográficos e documentais acerca dos sistemas de informação governamentais estudados.

Conhecer mais sobre os trâmites internos de um setor que tem crescido tão expressivamente, com expectativas de continuidade de sua evolução, focando em pontos que possuem tanta relevância como o fornecimento de dados que possibilitarão a construção de indicadores que nortearão a condução de programas, ações e políticas públicas, poderá contribuir com um maior esclarecimento sobre como acompanhar, entender e refletir criticamente sobre a gestão da EPT nacional.

\section{Censo escolar e Sistec}

O Censo Escolar pode ser definido como sendo uma pesquisa anual, realizada em âmbito nacional, de caráter declaratório, que é coordenada pelo Instituto Nacional de Estudos e Pesquisas Educacionais, um órgão ligado ao Ministério da Educação, e executado em parceria com as secretarias de educação estaduais e municipais, e as 
escolas da rede pública e privada do Brasil, mediante coleta descentralizada de dados de escolas, profissionais ligados a elas, infraestrutura, matrículas, rendimento escolar e movimento dos alunos nas turmas, por nível, etapa e modalidade de ensino. $O$ diretor ou pessoa responsável designada pela unidade escolar é quem declara todos os dados ao Censo Escolar.

Seu preenchimento é obrigatório para todas as escolas, públicas e privadas, que ofertam educação básica e profissional de nível médio, em suas diferentes etapas e modalidades. Há um aparato legal, constituído por uma série de documentos oficiais e legislações que definem a finalidade, obrigatoriedade, responsabilidades, deveres, periodicidade, bem como, o sistema de coleta dos dados do Censo Escolar. O Inep utiliza como sistema de coleta dos dados escolares o Educacenso, que é um sistema que faz uso de ferramentas web na coleta, organização, transmissão e disseminação dos dados censitários, mediante o cruzamento de quatro cadastros de dados: escola, turma, aluno e profissional escolar. Em linhas gerais, Diniz (1999) esclarece que o Censo Escolar não pode ser visto como um mero instrumento de coleta de dados, ele vai muito além, pois é a partir dele que são estabelecidas políticas de correção dos desequilíbrios regionais e de promoção da equidade na oferta do ensino público.

De acordo com o Inep os dados do Censo Escolar possibilitam o acompanhamento e avaliação dos sistemas de ensino do país e "são essenciais para a realização de análises e estudos comparados, subsidiando a formulação de políticas públicas para distribuição dos recursos" (BRASIL, 2011). Esse fato, de acordo com Diniz (1999), tem sua relevância aumentada em países como o Brasil, por possuir um sistema educacional extremamente desigual e descentralizado. De posse de dados do Censo Escolar o governo federal, em parceria com secretarias de educação estabelece políticas de correção dos desequilíbrios regionais.

O Censo Escolar, além de embasar todo o percurso de políticas públicas, também serve como uma ferramenta que demonstra a situação educacional do país, regional e nacionalmente e, para o Inep, ele é um importante instrumento formador de diagnósticos educacionais que auxilia no desenvolvimento de estratégias para acesso, permanência e êxito dos alunos em suas escolas, por proporcionar a obtenção de dados relativos ao rendimento dos alunos - aprovação e reprovação - e movimento - abandono e transferência - do ensino fundamental, médio e profissional. Esses dados associados a outras avaliações do Inep, como o Sistema de Avaliação da Educação Básica e Prova Brasil, constituem o cálculo do Índice de Desenvolvimento da Educação Básica, que serve de referência para as metas do Plano de Desenvolvimento da Educação do MEC.

O Sistec foi implantado pelo MEC no ano de 2009, por meio da Secretaria de Educação Profissional e Tecnológica - Setec -, que identificou problemas de compatibilização com o Censo Escolar e falta de dados necessários à sua análise acerca da educação profissional e tecnológica no Brasil. É considerado inovador por apresentar mensalmente informações sobre cursos técnicos de nível médio, respectivas escolas e alunos desse nível de ensino. Ele também é responsável por validar nacionalmente os diplomas de nível técnico. Todas as unidades de ensino credenciadas para oferta de cursos técnicos de nível médio, independentemente da sua categoria administrativa públicas ou privadas -, sistema de ensino: federal, estaduais ou municipais, e nível de autonomia, devem ser cadastradas no Sistec. 
O Sistec foi desenvolvido e implantado pela Setec/MEC com a intenção principal de prover o governo de dados que permitissem a elaboração de indicadores educacionais confiáveis e que permitissem a construção e implementação de estratégias, ações e políticas que desenvolvessem e fortalecessem a educação profissional e tecnológica nacional, seguindo as orientações do PNE.

Mesmo tendo um ponto de partida claro os usos e expectativas sobre o Sistec foram sendo ampliados e mais finalidades e responsabilidades passaram a fazer parte de seu programa, entre eles, pode-se citar, servir como um instrumento de validação nacional e consulta dos diplomas da EPT, não com o objetivo de substituir os trâmites legais para a emissão dos diplomas em cada Estado, nem o diploma físico que seguirá sendo emitido e registrado por cada unidade de ensino. O Sistec passou a atestar que os dados já foram previamente validados tanto pelos órgãos reguladores de cada Estado quanto pelas unidades de ensino responsáveis, atribuindo um código autenticador para cada registro. A validação nacional de diplomas pretende impedir que instituições irregulares continuem funcionando e também acabar com a falsificação de diplomas.

O Sistec também atua como instrumento fiscalizador do Acordo de Gratuidade do Sistema S - Sesc, Sesi, Senai e Senac -, oferecendo um painel de indicadores que possibilita ao governo acompanhar o seu cumprimento por parte das entidades envolvidas. Esse acordo foi firmado em 2008 entre o governo federal e Senai e Senac e previa um programa progressivo de comprometimento de gratuidade dessas entidades. De acordo com o Sistec, inicialmente, o acordo foi realizado por meio de um protocolo de compromisso celebrado entre o MEC, o Ministério do Trabalho e Emprego, o Ministério da Fazenda, a Confederação Nacional do Comércio de Bens, Serviços e Turismo, o Senac, o Sesc, o Senai e o Sesi, por meio dos decretos n. 6.635 e n. 6.633 de 2008, que regulamentavam e estipulavam como se daria o aumento do repasse dos recursos da receita de contribuição compulsória líquida para o Senai e Senac, em troca da evolução da quantidade de matrículas gratuitas de cursos técnicos ou de qualificação profissional.

O Sistec orienta algumas políticas e programas do MEC e tem o Programa Nacional de Acesso ao Ensino Técnico e Emprego - Pronatec - como um de seus principais programas e que integra cinco outros: Expansão da Rede Federal de Educação Profissional, Científica e Tecnológica; Programa Brasil Profissionalizado; Rede e-Tec Brasil; Acordo de Gratuidade com os Serviços Nacionais de Aprendizagem; e a Bolsa Formação.

O Pronatec foi instituído em 2011, a partir da lei n. 12.513, e tem como principais objetivos, "expandir, interiorizar e democratizar a oferta de cursos de educação profissional e tecnológica no país", além de buscar "ampliar as oportunidades educacionais e de formação profissional qualificada aos jovens, trabalhadores e beneficiários de programas de transferência de renda" (Brasil, 2011). O Sistec tornou-se ferramenta de gerenciamento de duas ações do Pronatec: a bolsa-formação, que se divide em bolsa-formação estudante e bolsa-formação trabalhador e o Fundo de Financiamento Estudantil para cursos técnicos. Cabe ressaltar também a Rede e-Tec Brasil, que é um programa federal que visa à oferta de EPT na modalidade à distância, e que também é gerenciado pelo Sistec, pelo mapeamento da oferta dos polos de apoio presencial em todo Brasil. 
A partir da lei n. 11.892, de 2008, que criou a Rede Federal de Educação Profissional Científica e Tecnológica e instituiu os institutos federais, o Sistec passou a servir de base para matriz orçamentária dos institutos federais, o que foi permitido por meio de um termo de acordo de metas e compromissos firmado entre o MEC e a rede federal.

Todos os dados das ofertas de matrículas dos alunos e cursos de instituições federais de EPT, cadastrados no Sistec, geram indicadores para os institutos federais e possibilitam a composição automática de sua matriz orçamentária, o que permite a liberação de recursos por meio da descentralização orçamentária entre o MEC e sua rede federal.

A seguir é apresentado o quadro 1, que traz um panorama geral comparativo entre o funcionamento e fases de abastecimentos do Censo Escolar e Sistec.

\section{Quadro 1 -}

Comparativo entre funcionamento e fases de inserções do Censo Escolar e Sistec.

\begin{tabular}{|c|c|c|}
\hline & CENSO ESCOLAR & SISTEC \\
\hline $\begin{array}{l}\text { PRAZOS/ } \\
\text { DATA BASE }\end{array}$ & $\begin{array}{l}\text { Os dados inseridos têm como data base } \\
\text { a última quarta-feira do mês de maio do } \\
\text { ano letivo corrente }\end{array}$ & $\begin{array}{l}\text { O prazo para cadastrar um ciclo de } \\
\text { matrícula vai até o dia } 25 \text { do mês seguinte à } \\
\text { data de início das aulas. E as atualizações } \\
\text { nos status dos alunos devem ser mensais }\end{array}$ \\
\hline $\begin{array}{l}\text { QUEM } \\
\text { DEVE } \\
\text { ABASTECER }\end{array}$ & $\begin{array}{l}\text { Todas as instituições que ofertam } \\
\text { educação básica, em suas diferentes } \\
\text { modalidades: Ensino Regular (Educação } \\
\text { Infantil, Ensinos Fundamental e Médio), } \\
\text { Educação Especial, Educação de Jovens e } \\
\text { Adultos (EJA) e Educação Profissional } \\
\text { (cursos técnicos e cursos de formação } \\
\text { inicial continuada ou qualificação } \\
\text { profissional) }\end{array}$ & $\begin{array}{l}\text { Todas as instituições de ensino que } \\
\text { ofertam cursos de todos os níveis, infantil, } \\
\text { fundamental, médio, formação inicial e } \\
\text { continuada (FIC), técnico de nível médio, } \\
\text { graduações e pós-graduações, que } \\
\text { trabalham com educação profissional e } \\
\text { tecnológica no país }\end{array}$ \\
\hline $\begin{array}{l}\text { DADOS } \\
\text { GERAIS }\end{array}$ & $\begin{array}{l}\text { Dados sobre estabelecimentos de } \\
\text { ensino, turmas, alunos, profissionais } \\
\text { escolares em sala de aula, movimento e } \\
\text { rendimento escolar }\end{array}$ & $\begin{array}{l}\text { Dados sobre administração, Ciclo de } \\
\text { matrículas, alunos, validador de diplomas, } \\
\text { e-Tec, Cursos e PRONATEC }\end{array}$ \\
\hline \multirow{5}{*}{$\begin{array}{l}\text { FASES DAS } \\
\text { INSERÇÕES }\end{array}$} & $\begin{array}{l}\text { 1. Escola: Dados cadastrais, } \\
\text { Caracterização e Infraestrutura, } \\
\text { Equipamentos, Recursos Humanos e } \\
\text { Dados educacionais. }\end{array}$ & 1. Unidade remota \\
\hline & 2. * Cadastro de turma & 2. Curso \\
\hline & 3. *Cadastro de aluno & $\begin{array}{l}\text { 3. * Cadastro, exclusão e atualização do } \\
\text { ciclo de matrícula }\end{array}$ \\
\hline & \multirow{2}{*}{ 4. Profissional escolar em sala de aula } & $\begin{array}{l}\text { 4. * Cadastro, exclusão e atualização de } \\
\text { status de aluno }\end{array}$ \\
\hline & & $\begin{array}{l}\text { 5. Cadastro e exclusão de polo da Rede e- } \\
\text { Tec }\end{array}$ \\
\hline
\end{tabular}

Fonte: Elaboração da autora. 


\section{Principais dificuldades com o uso dos sistemas governamentais sob a ótica de usuários}

Diante de todo o levantamento de dados e informações obtidas, produziu-se uma síntese que segue, a qual apresenta os pontos de maiores dificuldades e divergências em relação ao que os sistemas se propõem, junto aos apontamentos colhidos com os sujeitos entrevistados. Todos os quesitos apontados podem prejudicar o trabalho de inclusão de dados e reduzir a confiabilidade do que é apresentado:

1. Apesar de os sistemas possuírem legislações que determinam a obrigatoriedade de registro de instituições de ensino que ofertam EPT em informar todos os seus alunos e ciclos/turmas, nem todos os estabelecimentos o fazem. Não há um critério que tenha sido identificado para se optar ou não pelo abastecimento dos sistemas.

2. Pouco controle sobre dados referentes a rede privada de EPT.

3. Falta de fiscalização e avaliação do trabalho de abastecimento por parte dos órgãos responsáveis pelos SI.

4. Diferentes possibilidades de "Situação de alunos" entre os sistemas, a falta de clareza do que significa cada uma das opções, bem como, a falta de status que reflitam a real situação do discente, aumentando as chances de erros e diferenças em relação aos números reais da instituição.

5. Sistemas considerando somente ingressos e cursos anuais para EPT que, na maioria dos casos, opera com cursos semestrais.

6. Não há suporte nem treinamento adequados para o uso dos sistemas.

7. Existem muitas instabilidades nos sistemas durante os períodos de inserções.

8. Falta de relatórios que possam ser personalizados.

9. Pouco prazo previsto para correções.

10. Alguns dados são alterados pelos sistemas e algumas atualizações efetuadas pelos usuários não são registradas.

11. Falta de comprometimento dos gestores das instituições de ensino em averiguar seus dados declarados.

12. Pouca clareza e objetividade em relação aos motivos de existência, importância e finalidade de cada portal.

13. Falta de integração entre as ações e perspectivas do governo para a educação.

14. Falta de confiança nas estatísticas divulgadas pelo governo, em virtude do descrédito das plataformas para coleta de dados.

15. Pouco esclarecimento, divulgação e praticidade no uso das funcionalidades dos sistemas.

16. Desvalorização dos usuários diretos dos sistemas, que não participam de processos de avaliação e sugestões para melhorias nos seus usos e operacionalidades.

\section{Considerações finais}

A educação profissional e tecnológica tem assumido um papel importante no acesso às conquistas científicas e tecnológicas para toda população (Brasil, 2016). Muitos investimentos foram destinados a fortalecer e expandir a educação profissional nacional 
nos últimos anos. Programas foram implementados, outros extintos, mas, por meio dos dados utilizados pelo governo provenientes do Censo Escolar e Sistec não se tem a verdadeira dimensão da efetividade social que a grande vulta de recursos públicos tem retornado à população.

Os dados e informações coletadas mostraram uma série de inconsistências no que tange funcionamento, armazenamento e tratamento das extrações efetuadas a partir dos sistemas trabalhados e apontaram também para a insuficiência e pouca efetividade de seus suportes, treinamentos, fiscalização e avaliação que, provavelmente, interferem na construção de cenários fidedignos e, por conseguinte, atrapalham o planejamento e execução de uma gestão pública educacional efetiva.

Assim, o Censo Escolar e o Sistec podem ser aprimorados e devem ser melhor explorados frente a importância que possuem para o governo, enquanto bancos oficiais de dados. Deve ocorrer um forte trabalho de conscientização dos usuários que fazem a inserção de seus dados, um acompanhamento sobre o perfil dos profissionais que saem desse sistema deve ser construído, a fim de que suas deficiências possam ser sanadas.

Espera-se que esse trabalho possa ter contribuído com a construção de conhecimento sobre a EPT, suas bases de dados e pontos principais de dificuldades de uso, colaborando com futuras pesquisas que possam se aprofundar em temas que melhorem a efetividade da educação profissional e tecnológica do Brasil.

\section{Referências}

BRASIL. Lei n. 9.394, Lei de diretrizes e bases da educação nacional. Dezembro de 1996. Brasília, 1996.

BRASIL. Decreto n. 2.208, regulamenta a educação profissional, abril de 1997. Brasília, 1997.

BRASIL. Decreto n. 5.154, regulamenta a educação profissional, dezembro de 2004. Brasília, 2004.

BRASIL. Decreto n. 787, regulamenta a educação profissional, dezembro de 2004. Brasília, 2004.

BRASIL. Lei n. 11.892, Lei que institui os Institutos Federais, dezembro de 2008. Brasília, 2008.

BRASIL. Lei n. 12.513, Lei que institui Pronatec, dezembro de 2011. Brasília, 2011.

BRASIL. Ministério da Educação. Disponível em: https://www.mec.gov.br. Acesso em 13 de março de 2018.

BRASIL. Histórico da educação profissional. Disponível em http://portal.mec.gov.br/setec/arquivos/centenario/historico educacao profissional.pdf.

Acesso em 10 mar. 2018.

BRASIL. Sistec. Disponível em http://sitesistec.mec.gov.br/consulta-publica. Acesso em 13 mar. 2018.

BRASIL. Censo escolar. Disponível em http://portal.inep.gov.br/web/guest/censo. Acesso em 13 mar. 2018.

DINIZ, Ednar Maria Vieira. O censo escolar. Revista Brasileira de Estudos Pedagógicos, Brasília, v. 80, n. 194, 1999, p. 156-163. 
MARCONI, Marina de Andrade; LAKATOS, Eva Maria. Técnica de pesquisa: planejamento e execução de pesquisas, amostragens e técnicas de pesquisa, análise e interpretação de dados. São Paulo: Atlas, 2010.

Franciele de Lima Machado é servidora técnico-administrativo no Colégio TécnicoIndustrial de Santa Maria e tem mestrado em Educação Profissional e Tecnológica. Orcid: https://orcid.org/0000-0002-9374-8784.

Endereço: Visconde de Uruguai, 105 - 97450-500 - Santa Maria - RS - Brasil E-mail: fran Im20@hotmail.com.

Recebido em 3 de setembro de 2018.

Aceito em 10 de novembro de 2018.

(c) (i) 